\title{
Predicting Cognitive-Language and Social Growth Curves From Early Maternal Behaviors in Children at Varying Degrees of Biological Risk
}

\author{
Susan H. Landry \\ University of Texas Medical School-Houston \\ Cynthia L. Miller-Loncar \\ University of Texas Medical School-Houston
}

\author{
Karen E. Smith \\ University of Texas Medical Branch-Galveston
}

Paul R. Swank

University of Houston

\begin{abstract}
Growth modeling was used to examine the relation of early parenting behaviors (averaged across 6 and 12 months) with rates of change in children's cognitive-language and social response and initiating skills assessed at $6,12,24$, and 40 months. Groups of full-term $(n=112)$ and very low birth weight children, divided into medically low $(n=114)$ and high risk (HR; $n=73$ ), were included to evaluate whether children who vary in their rate of development are influenced in different ways by early parenting styles. Parenting behaviors that were sensitive to children's focus of interest and did not highly control or restrict their behaviors predicted greater increases and faster rates of cognitive-language and social development, with relations stronger for the HR versus the other two groups. These maternal behaviors may provide the support all infants need to establish an optimal early foundation for later development and the specific support HR children need to learn in spite of early attentional and organizational problems.
\end{abstract}

Across the past several decades, studies have examined aspects of early parenting that promote children's competencies, such as cooperation, self-assertion, initiative, and independence in problem solving (e.g., Belsky, Goode, \& Most, 1980; Bornstein \& Tamis-LeMonda, 1989; Kopp, 1982; Kuczynski, 1984). An optimal style of parenting for promoting social and cognitive competence is described as one that fosters reciprocal interactions between parent and child so that the child has some degree of control in the interaction (e.g., Baumrind, 1966; Bruner, 1977; Parpal \& Maccoby, 1985). In addition, parents' attentiveness to children's involvement state (e.g., Akhtar, Dunham, \& Dunham, 1991; Schaffer \& Crook, 1980; Tomasello \& Farrar, 1986) and their support and contingent responsiveness to children's interests and needs (e.g., Bornstein \& Tamis-LaMonda, 1989; Lewis \& Goldberg, 1969) are important aspects of parenting for understanding more optimal outcomes.

Reciprocal and responsive parenting is thought to promote children's cognitive and social-emotional development (Rocissano, Slade, \& Lynch, 1985). In relation to children's cognitive development, a mother's attempts to make requests that are sen-

Susan H. Landry and Cynthia L. Miller-Loncar, Department of Pediatrics, Division of Developmental Pediatrics, University of Texas Medical School-Houston; Karen E. Smith, Department of Pediatrics, University of Texas Medical Branch-Galveston; Paul R. Swank, Department of Educational Psychology, University of Houston.

This study was supported by National Institutes of Health Grant HD24128.

Correspondence concerning this article should be addressed to Susan H. Landry, University of Texas Medical School-Houston, Department of Pediatrics, Division of Developmental Pediatrics, P.O. Box 20708, Houston, Texas 77225. Electronic mail may be sent via Internet to slandry@pedl.med.uth.tmc.edu. sitive to her young child's current focus of interest support the child's more limited capacity to process information because the child is not required to shift attentional focus (Bloom, Rocissano, \& Hood, 1976; Tomasello \& Farrar, 1986). The child is then able to use his or her cognitive and attentional skills to provide a relevant response. In relation to children's socialemotional development, a mother who makes requests that are responsive to the child's current activities and is emotionally available is thought to give her child the message that his or her interests are important (Bornstein \& Tamis-LeMonda, 1989; Emde, 1985). In addition, a child's need for a sense of autonomy is recognized and accepted. This parenting style may have a motivational effect on the child by promoting his or her willingness to cooperate and to take an active role in learning (MacDonald, 1992). In the context of an effectance model, parental interactions that include a high degree of contingent responsiveness to the child's interests are hypothesized to help children learn that they can have an effect on their environment and learning (Bornstein \& Tamis-LeMonda, 1989; Lewis \& Goldberg, 1969). When parents are highly responsive to children's signals and interests, normally developing children show more cooperation and acceptance of parental suggestions (Matas, Arend, \& Sroufe, 1975; Parpal \& Maccoby, 1985; Schaffer \& Crook, 1980) and better cognitive and language outcomes (Bornstein \& Tamis-LeMonda, 1989; Bradley \& Caldwell, 1976; Olson, Bates, \& Bayles, 1984; Tomasello \& Farrar, 1986). In contrast, studies examining styles that implicitly lack in reciprocity (e.g., restricting, punishing, threatening) report a negative influence of this style on healthy full-term (FT) children's cognitive and social development (e.g., Crockenberg \& Litman, 1990; Maccoby \& Martin, 1983; Power \& Chapieski, 1986; Weiss, Dodge, Bates, \& Pettit, 1992).

Relations between reciprocal and responsive parenting with 
children's social and cognitive skills have been examined concurrently (e.g., Parpal \& Maccoby, 1985; Rocissano et al., 1985; Schaffer \& Crook, 1980) as well as by studies examining the relation of early parenting with children's later outcomes (e.g., Londerville \& Main, 1981). Little is known, however, about how these early parenting factors predict individual differences in the rate at which children acquire cognitive and social skills. Because a major goal of developmental psychology is to understand change in a child's acquisition of skills, examination of this question is important (McCall, 1977). Growth modeling, which examines individual differences in development in terms of rate of change (slope) and changes in the rate of change (curvature), is one approach that can assess whether early responsive and sensitive parenting styles influence levels of functioning or rates of change in children's skill development (Bryk \& Raudenbush, 1992; Willett, 1989).

Growth modeling may be a particularly valuable means of determining whether children who show different rates of development show different patterns of relations between specific early parenting behaviors and growth in social and cognitive processes. Very low birth weight (VLBW) infants of varying degrees of early medical risk are one group who may require more specialized parenting to optimize their development because, as a group, they show slower rates of growth in cognitive and social skills through 3 years of age as compared with FT infants (Landry, Denson, \& Swank, 1997). Whereas growth appears slower for VLBW infants as a group, as within any group, there are individual differences in this growth suggesting that some children, will show faster rates of gains than will others (Landry et al., 1997).

Early parenting behaviors that support VLBW infants' early difficulties in shifting their attentional focus and organizing their behavior is an interactive style that may explain accelerated development within groups of VLBW children (Landry, Leslie, Fletcher, \& Francis, 1985). When mothers make requests that maintain versus redirect VLBW infants' interests, these infants may show greater increases in skills because their mothers' support is specialized to their needs. Because FT infants do not have the same difficulty in shifting attentional focus or in organizing a response as do VLBW infants, their mothers' sensitivity to their attentional focus, although helpful in fostering development, may not be as essential in explaining individual differences in their rates of development. In a recent study, maternal requests that maintained rather than redirected infants' current focus of interest in a toy resulted in a greater increase in exploratory play for the high risk (HR) VLBW infants compared with low risk (LR) and FT infants (Landry, Garner, Swank, \& Baldwin, 1996). Maternal sensitivity has been associated with more positive affect for preterm infants with severe respiratory complications (Plunkett \& Meisels, 1989) and with growth in cognitive, language, and social abilities from 6 to 12 months of age for the VLBW infants included in the present article (Landry, Miller-Loncar, \& Smith, in press; Smith, Landry, Swank, Baldwin, Denson, \& Wildin, 1996). Reciprocal and responsive parenting across the first year of life may be particularly important for VLBW children because it models appropriate responding at an age when these infants are less capable of being responsive partners. When VLBW children receive early negative modeling (i.e., high control, restric- tiveness), they may be less likely at later ages to show appropriate social skills without high degrees of external control. In separate studies with VLBW children, higher parental control predicted poorer social skills at 3 years of age (Landry, Chapieski, Richardson, Palmer, \& Hall, 1990) and lower early cognitive skills, especially when more controlling styles were combined with insensitivity to the infants' interests (Landry \& Chapieski, 1989).

Sensitive parenting may be particularly important across the first year of life because VLBW infants' early attentional and organizational difficulties (Goldberg, Lojkasek, Gartner, \& Corter, 1989; Landry, Miller-Loncar, \& Smith, in press) interfere with their early learning. Rovee-Collier (1995) emphasized the importance of successful early learning experiences in a process she describes as "time windows." In this process, infants develop networks of associations through their experiences with the environment by assimilating new information with information in their memory from a previous related experience. Infants will develop more efficient memories (i.e., learned skills) when they have had a series of successful early learning experiences that occur while the previous memory is still retained. For VLBW infants, particularly those with more severe medical problems, having more successful learning experiences on which to build networks of associations may be more dependent on parents' providing early specialized support. The provision of support that allows them to have successful learning experiences, in spite of attentional and organizational delays, may establish a more optimal foundation on which later, more complex cognitive and social behaviors are built.

In the present study, we included groups of VLBW and FT children to evaluate whether children who vary in their rate of social and cognitive-language development from 6 to 40 months of age are influenced in different ways by parenting styles that occur during the first year. Using growth modeling analyses, we examined whether mothers who showed higher levels of attentiveness to children's current focus of interest and warm responsiveness, and lower levels of controlling directive and restrictive styles (i.e., more optimal parenting), promoted faster increases in cognitive-language and social development for FT as compared with VLBW children. Higher levels of this more optimal style were hypothesized to predict faster rates of cognitive-language and social development for all children. Because VLBW infants who experience more severe medical complications have greater difficulty in shifting their attentional focus (Landry et al., 1985) and in understanding contingencies between their behaviors and responses from their caretakers (Landry et al., 1996), we hypothesized that maternal behaviors that were directly responsive to these difficulties would show stronger relations for these infants as compared with the VLBW children with less severe medical complications and the FT children. Because of consistent reports regarding a negative influence of directive and restrictive parenting, these two parenting behaviors were hypothesized to predict slower rates of cognitive-language and social development for all children. Again, because of medically HR children's increased need for specialized parenting styles to take an active role in their learning, we expected these negative relations to be stronger for these children as compared with the other two groups. Because preterm infants of lower degrees of medical risk also have been reported 
to have early attentional and organizational difficulties (Goldberg et al., 1989) and, in previous studies, have shown different relations with particular parenting behaviors than have FT children (Landry, 1995), these relations were expected to be stronger for the lower risk VLBW children as compared with FT children.

\section{Method}

\section{Participants}

A cohort of 368 low socioeconomic status (SES) families recruited from 1990 through 1992 were evaluated in a longitudinal study of parenting behaviors and developmental outcomes in preterm VLBW infants. Fifteen percent attrition over the 6- to 40-month period was attributable primarily to families moving outside the study area. This report includes data from VLBW infants and FT infants and their female primary caregivers, who were all seen in the home when infants were $6,12,24$, and 40 months of age. VLBW infants' ages were corrected for prematurity.

VLBW infants were included if they weighed less than $1600 \mathrm{gm}$ and had a gestational age less than 36 weeks at birth. They were divided into medically HR and LR groups on the basis of the presence of specific medical complications (e.g., bronchopulmonary dysplasia, BPD, severity of intraventricular hemorrhage, IVH) that have been associated with delayed or abnormal developmental outcomes in follow-up studies with other samples of VLBW children (Bendersky \& Lewis, 1990; Landry, Fletcher, Denson, \& Chapieski, 1993; Vohr, Bell, \& Williamson, 1982).

The FT infants $(n=112)$ had gestational ages of 37 to 42 weeks, 1- and 5-min Apgar scores greater than 8, and a normal pregnancy history and physical exam at birth. They were recruited from the same hospitals as were the VLBW infants to assure similar socioeconomic and ethnic backgrounds.

The HR infants $(n=73)$ were diagnosed with one or more severe medical complications, including BPD, severe IVH, periventricular leukomalacia (PVL), or some combination of the three. BPD was documented by the need for oxygen for more than 28 days. Severe IVH was defined as a hemorrhage with progressive ventricular dilatation, as observed on the infant's third-week cranial ultrasound. Periventricular leukomalacia was also documented by cranial ultrasound, with characteristic findings of ischemic lesion of the periventricular white matter. Ninety-four percent of infants in the HR group had BPD (45\% without IVH, $40 \%$ with mild IVH, $9 \%$ with severe IVH, PVL, or both). The remaining $6 \%$ had either severe IVH, PVL with milder severities of respiratory distress, or both.

The LR infants $(n=114)$ were diagnosed with one or more less severe medical complications, including transient respiratory distress of the newborn and respiratory distress syndrome, in which oxygen was required for less than 28 days. Infants with milder grades of IVH (Grades I and II) without dilatation were also included.

Infants were excluded from participation in the study if they were diagnosed with significant sensory impairments, meningitis, encephalitis, symptomatic congenital syphilis, congenital abnormality of the brain, short bowel syndrome, or if they were positive for HIV antibody. They were also excluded if the primary caregiver was under 16 years of age, was a drug abuser, or spoke only Spanish. Eleven percent of parents approached for participation in the study declined. No differences were found on a broad range of demographic and medical characteristics between infants whose parents chose to participate and those who declined.

Prior to the home visit at 6 months of age, each infant's primary caregiver was identified in a structured interview that documented who was primarily responsible for feeding, bathing, and attending to the infant during the week and on weekends. For $98 \%$ of the infants, the primary caretaker was the biological mother; for the rest, it was usually the maternal grandmother.

Table 1 shows demographic and medical information for the three groups. Significant differences across groups were found in gestational ages, $F(2,305)=1462.32, p<.0001$, and birth weights, $F(2,305)$ $=819.87, p<.0001$, with the HR infants having significantly younger gestational ages and lower birthweights than do the LR and FT children and the LR infants having younger gestational ages and lower birth weights than do the FT children. The HR children had longer hospitalizations at birth than did the LR children $F(1,190)=70.74, p<.0001$. No significant differences were found across groups on mothers' education, SES, or ethnicity, and infant gender. Mothers of VLBW infants were significantly older ( $M=2$ years) than were mothers of FT infants, $F(2,305)=5.57, p<.05$.

\section{Procedure}

Maternal behaviors and infant social skills were assessed at 6,12 , 24 , and 40 months of age during a home visit that included a $60-$ min naturalistic period of daily activity. To assure that families were comfortable with the study procedures, preliminary visits to the family were made where possible to discuss the study and to answer questions before the first home observation. Language skills were assessed at all age points with the Sequenced Inventory of Communication Development (SICD, Receptive and Expressive scales; Hedrick, Prather, \& Tobin, 1975). The SICD provides separate age scores for Expressive and Receptive Language skills. Children's cognitive skills were assessed at 6 , 12, and 24 months of age with the Bayley Scales of Infant Development-Mental scale (Bayley, 1969) and, at 40 months of age, with the Stanford-Binet Intelligence Test-Fourth Edition (SB-4; Thorndike, Hagen, \& Sattler, 1986). When changing measures, a question arises as to whether the use of different measures across time results in models of cognitive growth that reflect development versus changing measurement instruments (Crocker \& Algina, 1986; Sax, 1980). We conducted a scaling procedure on a subset of 22 children assessed at 26 to 28 months of age with the Bayley mental scale and SB-4. These data revealed that Bayley items correlated significantly with SB-4 items at the same point in time $(p<.05)$. Correlations for the full sample between the SB-4

Table 1

Medical and Demographic Characteristics of the Sample by Risk Group

\begin{tabular}{|c|c|c|c|c|c|c|}
\hline \multirow{3}{*}{$\begin{array}{l}\text { Demographic } \\
\text { characteristic }\end{array}$} & \multicolumn{6}{|c|}{ Risk group } \\
\hline & \multicolumn{2}{|c|}{ High risk } & \multicolumn{2}{|c|}{ Low risk } & \multicolumn{2}{|c|}{ Full-term } \\
\hline & $M$ & $S D$ & $M$ & $S D$ & $M$ & $S D$ \\
\hline Birth weight (g) & 917 & $232_{\mathrm{a}}$ & 1,261 & $191_{b}$ & 3,229 & $677_{\mathrm{c}}$ \\
\hline Gestation (wks) & 28.0 & $2.2_{\mathrm{a}}$ & 30.9 & $2.0_{\mathrm{b}}$ & 40.0 & $0.4_{c}$ \\
\hline Hospitalization (days) & 115 & $83_{\mathrm{a}}$ & 41.4 & $37_{b}$ & - & - \\
\hline Socioeconomic status ${ }^{a}$ & 29.6 & 12 & 29.2 & 11 & 26.0 & 9 \\
\hline Maternal age (yrs) & 29 & $7.4_{a}$ & 29 & $7.2_{\mathrm{a}}$ & 27 & $6.1_{b}$ \\
\hline Maternal education (yrs) & 12.2 & 2.0 & 12.3 & 2.0 & 11.7 & 1.7 \\
\hline \multicolumn{7}{|l|}{ Maternal ethnicity (\%) } \\
\hline African American & 54 & & 63 & & 65 & \\
\hline Caucasian & 26 & & 20 & & 21 & \\
\hline Hispanic & 15 & & 14 & & 14 & \\
\hline Other & 5 & & 3 & & 0 & \\
\hline \multicolumn{7}{|l|}{ Infant gender (\%) } \\
\hline Male/female & $51 / 49$ & & $39 / 61$ & & $52 / 48$ & \\
\hline
\end{tabular}

Note. Groups with different subscripts differ significantly.

${ }^{a}$ Socioeconomic status based on Hollingshead (1975) scale. 
at 40 months and the Bayley mental ages were as follows: 6 mos ( $r=$ $.21), 12$ months $(r=.32)$, and 24 months $(r=.58)$.

At the beginning of each home visit, the observers spent approximately $10 \mathrm{~min}$ with each family describing what would happen, answering questions, and interacting informally with the infant to enhance comfort and familiarity. During a naturalistic observation period, mothers were asked to go about their daily activity for 1 hour, staying in the same room with their children and to feed, bathe, or dress the child during that hour. No further structure was placed on the family, and observers followed the dyad into all parts of the home as the family went about their daily activities. Pencil and paper methods were used during observation, with one research assistant coding maternal interactive behaviors and one coding child social behaviors.

Child social competence. Two aspects of the children's social competence were coded; responsiveness to mothers' attention-directing behaviors and requests and initiations of social interactions. Children's social competence was examined from their interactions with their mothers in the home environment rather than with an examiner because children acquire their social skills at these young ages through interactions with their primary caretaker (Marfo, 1990). This approach was, therefore, expected to provide a more valid representation of their skills.

Children's social behaviors were coded as a response if they followed within $3 \mathrm{~s}$ of a maternal attention-directing event and as anitiation if they occurred when the mother had not interacted with the infant for at least $3 \mathrm{~s}$. Initiating behaviors were coded as separate events if they were separated by at least $3 \mathrm{~s}$. In previous cross-sectional studies with children of similar ages (Landry, Garner, Pirie, \& Swank, 1994), we found that if children were going to respond to their mothers' requests, the response most often occurred within the first 2 to $3 \mathrm{~s}$ after the completion of the request. If greater amounts of time were allotted, children's initiating behaviors were inappropriately coded as social responding.

Scoring of social behaviors. At all ages, social categories for responses and initiating behaviors included gestures, positive affect, eye gaze, and vocalizations/words. Two additional response categories included: (a) the infant's orienting to the focus of mother's attentiondirecting behavior at 6 months (Scaife \& Bruner, 1975) and (b) compliance and negotiating versus noncompliance to maternal requests at 24 and 40 months (Kuczynski \& Kochanska, 1990). Constructs of responses and initiations and the points assigned to each category within these constructs were based on the developmental sequence of behaviors documented in the social literature (e.g., Butterworth, 1995; Kopp, 1982) and confirmatory factor analyses, as described in our Results section. These analyses indicate that responses and initiations are distinct constructs of social competence and that separate categories of specific behaviors (i.e., smiles/affect, gesture/words, compliance) account for variability within these constructs, thus providing support for assigning different weightings for specific behaviors.

Categories of affect and eye gaze, which emerge in early infancy, were coded at all ages ( 1 point per category). Attention-directing gestures also were coded at all ages but received 2 points because this behavior begins to emerge at the end of the first year of life, after eye gaze and positive affect (Leung \& Rheingold, 1981). Children's social language skills were captured through a hierarchy of points assigned at each age based on the complexity of the verbal utterance. At 6 and 12 months of age, vocalizations were credited with 1 point. Because by 24 months, the use of words is a marker for more sophisticated social communicative competence, words received 2 points, whereas vocalizations continued to receive 1 point. To capture the importance of language skills at 40 months for effective social interactions, points were assigned on the basis of whether children used single words ( 1 point), brief but incomplete utterances ( 3 points), and complete sentences ( 5 points). In part, on the basis of Kuczynski and Kochanska's (1990) developmental study of noncompliance, in our study, compliance at 24 and 40 months received 3 points, negotiating received 4 points, and noncompliance received -2 points. Kuczynski and Kochanska found that across the toddler period, there is variability in children's ability to comply, with most children being adept at this skill by 3 years of age. However, the ability to assert social individuality through the use of negotiations was found to be a marker for more social sophistication because it did not emerge until after 2 years of age and was related to competence in directing others' attention.

To further validate this scoring system, expert raters viewed videotaped mother-child interactions at each of the four age points and ranked the children as high, medium, or low in social initiating and responses, for a subset of children whose interactions had also been scored with this system. To assure that children who had a broad range of developmental skills were included, scores from standardized testing were used to select children for inclusion in these three groups. Experts' rankings and those based on the scoring system showed agreement at .81 .

Separate social response and initiating age scores were calculated at each age from the coding system described above. Age scores were developed to provide data in a familiar unit when examining VLBW children's social skills relative to the FT children in the present sample. Because we did not have social data on a normative sample, these age scores were not interpreted as representative of normative social development but rather to highlight relative differences between risk groups. For the response age score, first, the total number of points obtained across all maternal attention directing events was divided by the total number of events. For the initiating age score, the total number of points obtained across all initiating events was divided by the total number of initiating events. Initiating and response age scores were developed in a similar manner, with the FT group as our standard. With the FT group, a weighting function was first derived with a regression procedure: The original response or initiating score was used to predict an age score. This equation was then used with each participant to obtain response and initiating age scores.

Maternal behaviors. Maternal behaviors were measured with molar (rating scale) and micro (frequencies of behaviors) methods (see Table 2 , for definitions) to reflect a broad range of maternal characteristics. A maternal attention-directing event was defined as any maternal verbal behavior (questions, comments, directives) or nonverbal behavior (orienting gestures, demonstrations, giving of objects) that was directed toward the infant. Separate events were coded when $3 \mathrm{~s}$ or more elapsed between maternal behaviors. When mothers gave rapid requests that did not allow time for an infant response, the series was coded as a single event.

Mothers' maintaining of children's focus of involvement, and their directive and restrictive behaviors, were coded as frequencies to examine the degree to which mothers' requests demonstrate a certain style. Proportions rather than frequencies were used in analyses to control for differences across mothers in how often they attempted to get their child's attention. Means and standard deviations by risk group and age point for each maternal behavior are presented in Table 3 (see Table 4, for intercorrelations). No significant differences were found among the mothers' behaviors based on infant risk.

Five-point rating scales were used to rate three aspects of mothers' sensitive and responsive behavior: positive affect, warm sensitivity, and contingent responsiveness (see Table 2). Bakeman and Brown (1980) have proposed that because maternal warm responsiveness is a dispositional variable, ratings are appropriate. Ratings were done every $20 \mathrm{~min}$ during daily activities. The three ratings taken across each home visit for each of the three behaviors were averaged to obtain a single score. Pearson product-moment correlations were calculated among the ratings for the three maternal behaviors to determine if they were significantly intercorrelated. Given the high degree of correlation among these three ratings across all time points (range, $r=.50$ to .80 ), scores were averaged to obtain a single composite measure that was labeled warm 
Table 2

Definitions of Maternal Behaviors

\begin{tabular}{|c|c|}
\hline Maternal behavior & Definition \\
\hline Frequency of stimulation & $\begin{array}{l}\text { The total number of maternal attempts to direct the infant's attention during } \\
\text { the observation period, including behaviors such as making a request, } \\
\text { orienting attention, or commenting }\end{array}$ \\
\hline Warm responsiveness & $\begin{array}{l}\text { Degree of sensitivity and responsiveness to infant's cues, including } \\
\text { promptness and appropriateness of mother's reactions, acceptance of } \\
\text { infant's interests and needs, amount of physical affection and positive } \\
\text { affect, positive tone of voice, appropriate pace that fits infant's abilities, } \\
\text { and avoidance of negative comments about the infant }\end{array}$ \\
\hline Maintaining & $\begin{array}{l}\text { Maternal request related to the activity or object the infant is currently } \\
\text { visually and physically engaged with, or in direct response to the infant's } \\
\text { attempts to attract mother's attention to an object or activity }\end{array}$ \\
\hline Directiveness & $\begin{array}{l}\text { Matemal strategies that provide more control and structure through } \\
\text { increased information and less choice; may be verbal (e.g., "put the ring } \\
\text { here") or nonverbal only (e.g., hands child a toy) }\end{array}$ \\
\hline Restrictiveness & $\begin{array}{l}\text { Any physical or verbal attempt by mother to stop what her child is doing } \\
\text { or saying }\end{array}$ \\
\hline
\end{tabular}

responsiveness. With Cronbach's alpha, internal consistency of the composite across ages ranged from 0.81 to 0.84 .

Interrater reliability. To estimate reliability, $20 \%$ of the home observations were coded by a second rater, during which mother's behaviors were coded for one half of the visit and child's behaviors during the other half of the visit. The second rater alternated the order of coding mother and child behaviors across home visits. Comparable numbers of mother-infant dyads across the three groups were included in the reliability sample to ensure that all groups were represented equally. Generalizability coefficients, which reflect the ratio of participant score variance over the sum of the participant score variance plus error variance (Cronbach, Gleser, \& Rajaratnam, 1963), were calculated for each maternal and infant variable. Coefficients for maternal and child social behaviors across the four time points were $(6 / 12 / 24 / 40$ months, respectively): maintaining $(r=.92 / .94 / .95 / .96)$; warm responsiveness $(r=.82 / .85 /$ $.84 / .84)$; directiveness $(r=.95 / .94 / .98 / .96)$; restrictiveness $(r=.98 /$ $.97 / .92 / .98)$; response $(r=.81 / .89 / .83 / .94)$; and initiating $(r=.94 /$ $.91 / .87 / .92)$.

Table 3

Mothers' Behaviors Averaged Over 6 and 12 Months of Age

\begin{tabular}{llll}
\hline & \multicolumn{3}{c}{ Risk group } \\
\cline { 2 - 4 } Maternal behavior & High risk & Low risk & Full-term \\
\hline Frequency of stimulation & & & \\
$M$ & 80.13 & 73.28 & 81.38 \\
$S D$ & 25.7 & 28.1 & 29.3 \\
Warm responsiveness (\%) & 11.07 & 10.68 & 10.64 \\
$M$ & 1.9 & 2.0 & 2.0 \\
$S D$ & & & \\
Maintaining (\%) & 28.93 & 29.15 & 29.26 \\
$M$ & 10.0 & 9.8 & 10.1 \\
$S D$ & & & \\
Directiveness (\%) & 50.14 & 49.52 & 49.10 \\
$M$ & 11.5 & 11.9 & 11.9 \\
$S D$ & & & \\
Restrictiveness $(\%)$ & 19.60 & 22.62 & 20.19 \\
$M$ & 14.4 & 14.2 & 12.9 \\
$S D$ & & & \\
\hline
\end{tabular}

\section{Results}

The effects of early parent and child characteristics on children's cognitive-language development and the development of social initiating and responses were examined with hierarchical linear modeling (HLM; Bryk \& Raudenbush, 1992). The dependent variables are scores collected at multiple age points and yield an individual growth curve for each participant, an approach similar to the random coefficient growth models of Cook and Ware (1983). With HLM, developmental growth can be assessed at a specific time point (intercept) as well as a rate of linear growth (slope) and nonlinear or changes in the rate of growth (curvature). Hierarchical linear modeling also allows between-individual correlates of the intercept, slope, and curvature to be examined through a multiple regression framework with maximum likelihood estimates. In the three HLM models, amount of stimulation, socioeconomic status, and mental age averaged across 6 and 12 months (in the two social models), or social initiating age and response age averaged across 6 and 12 months (in the cognitive-language model) were included as fixed effects to control for the effects of general parenting and specific child functioning on growth in skills. In each model, the independent variables of medical risk and all four parenting behaviors (i.e., warm responsiveness, maintaining, directiveness, and restrictiveness ) were also specified as fixed effects. The maternal behaviors were included as separate variables be-

Table 4

Intercorrelations for Mothers' Behaviors Averaged Over 6 and 12 Months of Age

\begin{tabular}{lrrrr}
\hline \multicolumn{1}{c}{ Maternal behavior } & 1 & 2 & 3 & 4 \\
\hline 1. Warm responsiveness & - & & & \\
2. Maintaining & $.22^{*}$ & - & & \\
3. Directiveness & $-.35^{*}$ & -.01 & - & \\
4. Restrictiveness & $-.50^{*}$ & $-.11^{*}$ & $.16^{*}$ & - \\
$* p<.05$. & & & &
\end{tabular}


cause we had specific hypotheses regarding how each of these behaviors would relate to children's development. The low-tomoderate shared variance among these four behaviors also supported this decision (see Table 3, for intercorrelations). The intercept for the three models was set at 18 months because this approach provided the most adequate reliabilities for the intercept, slope, and curvature as compared with the 6- and 12month time points (Bryk \& Raudenbush, 1992).

Because of specific questions regarding the differential influence of parenting behaviors with the child's biological risk, the interaction between biological risk and maintaining, warm responsiveness, directiveness, and restrictiveness were included as fixed effects. As we have specified directional hypotheses with both conceptual and empirical bases, planned orthogonal contrasts were used in evaluating the significance of interactions with biological risk and one-tailed tests were interpreted when directional hypotheses were supported (Maxwell \& Delaney, 1990). The first comparison evaluated differences for the HR versus the combined LR and FT groups (Contrast 1), and the second comparison evaluated differences between the LR and FT groups (Contrast 2). Nonsignificant interactions between parenting behaviors and medical risk for the three growth parameters were dropped from the models to obtain the most parsimonious model and avoid biasing the parameter estimates for the remaining terms (Pedhazur, 1982).

Significant relations between the predictors (e.g., risk, parenting behaviors) with the intercept provide information about the relation of the predictors with individual differences in the children's cognitive language and social status at 18 months. Results related to slope provide information about the relation between the predictors and linear changes in children's skills and those with curvature provide information about the relation with nonlinear changes in skill development. Significant interactions with risk demonstrate that these relations varied across the risk groups. The constant term for each growth parameter in each model provides information about the significance of that parameter when all predictors in the model are at zero.

\section{Support for a Cognitive-Language Construct}

A structural equation model specifying cognitive-language factors at the four age points was used to establish the validity and reliability for a cognitive-language construct. The indicator variables were mental age and expressive and receptive language age scores assessed at $6,12,24$, and 40 months of age (see Table 5). In the initial measurement model, the indicator variables loaded significantly at all four age points into a single cognitive-language factor (all path coefficients of $p<.05$ ), with $42 \%$ to $89 \%$ of the variance accounted for in each of the indicators. Validity of this construct across ages was demonstrated by an adequate fit for the model as indicated by multiple indices (root mean square error of approximation, RMSEA = $.05, p>.05$, goodness-of-fit index, GFI $=.96$, cumulative fit index, $\left.\mathrm{CFI}=.98, \chi^{2}[43, N=300]=81.6, p<.01\right) ; 41 \%$ to $74 \%$ of the variance was accounted for by this construct. Mental, expressive, and receptive ages shared significant amounts of variance, irrespective of age points. Although the chi-square index was significant, this was probably due to the large sample size because an additional criteria for an acceptable fit was met (i.e., chi-square to degrees of freedom ratio of less than 2 to 1). An alternative measurement model in which the three measures were hypothesized to be three separate constructs, with indicators assessed at each age point, did not show acceptable fit indices $($ RMSEA $=.19, p<.05$, GFI $=.72$, CFI $=.73$,

Table 5

Infant Developmental Behaviors Across Ages and by Risk Group

\begin{tabular}{|c|c|c|c|c|c|c|c|c|}
\hline \multirow{2}{*}{$\begin{array}{l}\text { Child measure } \\
\text { and risk group }\end{array}$} & \multicolumn{2}{|c|}{6 months } & \multicolumn{2}{|c|}{12 months } & \multicolumn{2}{|c|}{24 months } & \multicolumn{2}{|c|}{40 months } \\
\hline & $M$ & $S D$ & $M$ & $S D$ & $M$ & $S D$ & $M$ & $S D$ \\
\hline \multicolumn{9}{|l|}{ Cognitive mental age } \\
\hline High risk & 6.00 & 1.4 & 11.87 & 2.0 & 22.17 & 3.0 & 34.15 & 5.3 \\
\hline Low risk & 6.28 & 1.0 & 12.79 & 1.6 & 23.61 & 3.0 & 35.04 & 5.3 \\
\hline Full-term & 6.59 & 0.8 & 12.93 & 1.1 & 23.94 & 2.3 & 37.09 & 5.8 \\
\hline \multicolumn{9}{|c|}{ Expressive language age } \\
\hline High risk & 6.22 & 1.2 & 11.71 & 2.4 & 23.32 & 4.9 & 36.32 & 8.0 \\
\hline Low risk & 6.48 & 1.1 & 12.76 & 2.3 & 24.85 & 4.5 & 38.75 & 7.2 \\
\hline Full-term & 6.61 & 0.9 & 12.84 & 1.9 & 24.91 & 3.4 & 41.41 & 5.4 \\
\hline \multicolumn{9}{|c|}{ Receptive language age } \\
\hline High risk & 6.48 & 1.5 & 10.79 & 1.4 & 24.39 & 5.3 & 35.90 & 7.1 \\
\hline Low risk & 6.95 & 1.2 & 11.34 & 1.6 & 26.05 & 5.0 & 38.50 & 6.5 \\
\hline Full-term & 7.03 & 0.9 & 11.30 & 1.2 & 26.70 & 3.7 & 40.31 & 5.0 \\
\hline \multicolumn{9}{|c|}{ Social responsiveness age } \\
\hline High risk & 9.35 & 1.4 & 9.63 & 1.9 & 23.42 & 5.9 & 36.94 & 11.1 \\
\hline Low risk & 9.44 & 1.5 & 10.00 & $1: 8$ & 24.62 & 7.4 & 36.87 & 11.8 \\
\hline Full-term & 8.59 & 1.6 & 10.04 & 1.7 & 25.61 & 5.7 & 38.21 & 12.0 \\
\hline \multicolumn{9}{|l|}{ Social initiating age } \\
\hline High risk & 8.49 & 1.9 & 9.87 & 1.8 & 26.86 & 5.5 & 35.97 & 11.2 \\
\hline Low risk & 8.32 & 1.4 & 10.15 & 1.5 & 28.86 & 5.1 & 37.12 & 11.6 \\
\hline Full-term & 8.41 & 2.4 & 11.13 & 2.6 & 28.59 & 5.5 & 38.11 & 12.0 \\
\hline
\end{tabular}

Note. Data are converted to age scores (in months) with presentation of group mean and standard deviations. 
$\chi^{2}[51, N=300]=595.4, p<.01 ;$ significant chi-square and greater than $2: 1$ ratio).

\section{Prediction of Growth in Cognitive-Language Skills}

A random effects hierarchical linear model (HLM) that included no fixed-effects predictors and specified the intercept, slope, and curvature parameters was used to model growth and then was compared to a model assuming only linear changes to determine if the data best fit a linear or nonlinear model. The results indicated a significant curvature (i.e., quadratic) parameter, $\chi^{2}(3)=25.25, p<.01$; however, the variability of this parameter did not differ from zero, and so it was included as a fixed effect in the model. Although fixed-effects curvature findings cannot be interpreted for individual participants, interpretation regarding differences across risk groups are appropriate. The intercept and slope were significantly different from zero $(p<.0001)$ and thus were included as random effects. Reliabilities for the intercept and slope, intercorrelations between these parameters, and significant and nonsignificant predictors of cognitive-language growth are presented in Table 6 . Although there was a high correlation between the slope and the intercept, they each accounted for significant variability in the model and thus provide unique information to the model. Nonsignifcant interactions between maintaining and risk group for all three parameters were dropped from the final model.

When examining maternal predictors of children's cognitivelanguage ages at the 18-month intercept, no interactions with risk were found. For all groups, mothers who used higher proportions of maintaining strategies were more likely to have children with higher cognitive-language ages. However, mothers whose interactions were characterized by higher proportions of restrictiveness had children with lower cognitive-language ages. There was a tendency for higher proportions of early directiveness to relate to higher cognitive-language ages as well. In addition, children from families of higher SES and those with higher early social response ages were more likely to have higher cognitive-language ages at 18 months.

When examining linear growth (i.e., slope) in cognitive-language skills, as depicted in Figure 1, mothers' use of higher proportions of maintaining averaged over the first year of life related to a greater rate of increase in all children's cognitivelanguage ages. There was also a significant $H R$ versus $L R$ and FT group interaction for restrictiveness that indicated that mothers' use of higher proportions of restrictiveness related to lower rates of increase in children's cognitive-language ages, but this relation was stronger for the HR children compared with the other two groups. In addition, higher levels of SES and higher frequencies of stimulation were related to a greater rate of increase in cognitive-language ages.

Examination of nonlinear growth (i.e., curvature) revealed a trend in the constant term that indicates that faster growth in cognitive-language skills tends to occur at later ages for all children. A significant $H R$ versus LR/FT contrast indicated that faster growth at later ages was more apparent for the HR children than the other two groups. When examining the relation of mothers' early interactions to this later acceleration, those children across all groups whose mothers showed higher proportions of directiveness were less likely to show the same degree
Table 6

Predictors of Growth in Cognitive-Language Skills From 6 Through 40 Months

\begin{tabular}{|c|c|c|c|}
\hline Parameter and growth predictor & $\begin{array}{l}\text { Parameter } \\
\text { estimate }\end{array}$ & $t$ ratio & $p$ \\
\hline \multicolumn{4}{|l|}{ Child status at 18 mos: intercept ${ }^{\mathrm{a}}$} \\
\hline Constant & -2.23 & -0.54 & .59 \\
\hline SES & 0.11 & 3.81 & .000 \\
\hline Contrast 1: HR vs. LR/FT ${ }^{b}$ & 1.65 & 0.81 & .42 \\
\hline Contrast 2: LR vs. FT ${ }^{c}$ & -4.63 & -1.53 & .13 \\
\hline Social initiating & 0.06 & 0.29 & .77 \\
\hline Social responsiveness & 0.72 & 3.01 & .003 \\
\hline Warm responsiveness & 0.21 & 1.05 & .29 \\
\hline Total stimulation & 0.02 & 1.76 & .08 \\
\hline Maintaining & 0.08 & 3.11 & .002 \\
\hline Directiveness & 0.04 & 1.84 & .06 \\
\hline Restrictiveness & -0.07 & -3.16 & .002 \\
\hline Warm responsiveness: HR vs. LR/FT & -0.07 & -0.52 & .60 \\
\hline Warm responsiveness: LR vs. FT & 0.30 & 1.58 & .11 \\
\hline Directiveness: HR vs. LR/FT & -0.01 & -0.58 & .56 \\
\hline Directiveness: LR vs. FT & 0.05 & 1.71 & .08 \\
\hline Restrictiveness: HR vs. LR/FT & 0.01 & 0.84 & .40 \\
\hline Restrictiveness: LR vs. FT & -0.02 & -0.78 & .44 \\
\hline \multicolumn{4}{|l|}{ Linear growth rate: slope ${ }^{d}$} \\
\hline Constant & -2.22 & -0.78 & .44 \\
\hline SES & 0.06 & 3.13 & .002 \\
\hline Contrast $1:$ HR vs. $L R / F^{b}$ & -0.09 & -0.06 & .95 \\
\hline Contrast 2: LR vs. FT $^{\mathrm{c}}$ & -1.63 & -0.76 & .45 \\
\hline Social initiating & 0.09 & 0.62 & .54 \\
\hline Social responsiveness & 0.28 & 1.67 & .09 \\
\hline Warm responsiveness & 0.09 & 0.65 & .52 \\
\hline Total stimulation & 0.02 & 2.40 & .02 \\
\hline Maintaining & 0.05 & 2.70 & .007 \\
\hline Directiveness & 0.00 & 0.21 & .83 \\
\hline Restrictiveness & -0.03 & -1.76 & .08 \\
\hline Warm responsiveness: HR vs. LR/FT & 0.01 & 0.14 & .89 \\
\hline Warm responsiveness: LR vs. FT & 0.07 & 0.54 & .59 \\
\hline Directiveness: HR vs. LR/FT & -0.00 & -0.33 & .74 \\
\hline Directiveness: LR vs. FT & 0.02 & 1.29 & .19 \\
\hline Restrictiveness: HR vs. LR/FT & 0.02 & 1.99 & .04 \\
\hline Restrictiveness: LR vs. FT & -0.01 & -0.48 & .63 \\
\hline \multicolumn{4}{|l|}{ Nonlinear growth rate: curvature $^{\mathrm{e}}$} \\
\hline Constant & 2.11 & 1.65 & .09 \\
\hline SES & -0.01 & -0.63 & .53 \\
\hline Contrast $1:$ HR vs. LR/FT ${ }^{b}$ & -1.20 & -1.99 & .05 \\
\hline Contrast 2: LR vs. FT ${ }^{\mathrm{c}}$ & 1.18 & 1.25 & .21 \\
\hline Social initiating & 0.12 & 1.81 & .07 \\
\hline Social responsiveness & -0.12 & -1.61 & .11 \\
\hline Warm responsiveness & -0.03 & -0.45 & .65 \\
\hline Total stimulation & 0.00 & 0.94 & .35 \\
\hline Maintaining & -0.01 & -0.63 & .53 \\
\hline Directiveness & -0.02 & -3.21 & .002 \\
\hline Restrictiveness & -0.01 & -1.99 & .05 \\
\hline Warm responsiveness: HR ys. LR/FT & 0.06 & 1.66 & .09 \\
\hline Warm responsiveness: LR vs. FT & -0.11 & -1.83 & $.033 *$ \\
\hline Directiveness: HR vs. LR/FT & 0.01 & 1.06 & .29 \\
\hline Directiveness: LR vs. FT & -0.00 & -0.30 & .76 \\
\hline Restrictiveness: HR vs. LR/FT & 0.01 & 2.08 & .04 \\
\hline Restrictiveness: LR vs. FT & 0.01 & 0.72 & .47 \\
\hline \multicolumn{4}{|l|}{ Intercorrelations } \\
\hline Intercept & - & & \\
\hline Slope & 0.99 & - & \\
\hline
\end{tabular}

Note. Asterisk indicates one-tailed test. SES = socioeconomic status; $\mathrm{HR}=$ high risk; $\mathrm{LR}=$ low risk; FT $=$ full-term.

${ }^{\mathrm{a}}$ Reliability $=.82 .{ }^{\mathrm{b}}$ Contrast $1:$ HR $(-2)$ compared with LR (1) and FT (1) combined. ${ }^{\mathrm{c}}$ Contrast 2: LR (-1) compared to FT (1). ${ }^{\mathrm{d}}$ Reliability $=.80 .{ }^{e}$ Fixed. 


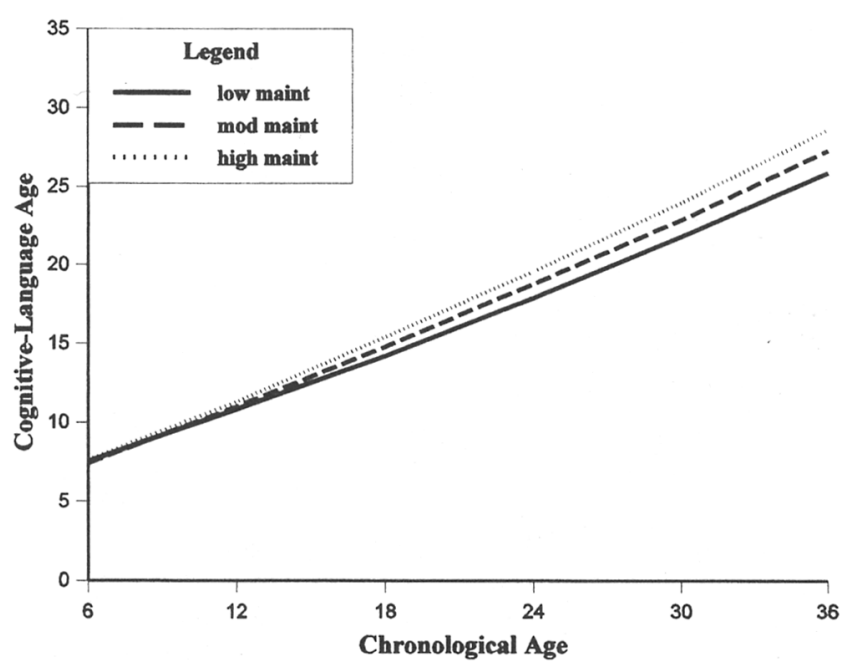

Figure 1. The relation of high, moderate, and low levels of maintaining with average growth in children's cognitive-language skills from 6 through 40 months of age across risk groups. Maint $=$ maintaining.

of acceleration. Mothers' use of higher proportions of restrictiveness also related to slower rates of later acceleration of cognitive-language skills; however, this was stronger for the HR as compared with the LR and FT children. In contrast, LR as compared with FT children whose mothers used more early warm responsiveness were more likely to show a greater degree of this later acceleration.

\section{Support for a Social Competence Construct}

To establish the validity and reliability for a social competence construct, a series of confirmatory factor and structural equation modeling analyses were done. The initial measurement model specified a social competence factor at each age point. The indicator variables were initiating and response ages assessed at $6,12,24$, and 40 months of age (see Table 5). The initial measurement model, in which initiations and responses were hypothesized to comprise a single construct at each age point, indicated that the model fit the data, $\chi^{2}(14, N=300)=16.5$, $p>.05$. However, the construct accounted for only $10 \%$ to $15 \%$ of the variance in each of the indicators. Further, although the coefficients for initiations and responses showed moderate relations at 24 and 40 months, they were not related at the 6- and 12-month age points.

A new structural equation model was examined to determine whether there were two distinct social factors (i.e., responses, initiations) at each age point. Confirmatory factor analyses revealed that social behaviors at 6 and 12 months for both responses and initiations included four indicators (i.e., gestures, smiles, eye gaze, vocalizations-words) that were then analyzed to assess the presence of single or multiple social constructs at these early ages. Results supported the presence of two constructs at 6 and 12 months of age that accounted for significant variability in these indicators; 6 months, responses (range; $r^{2}$ $=.46$ to .50 ), and initiations (range; $r^{2}=.19$ to .70$) ; 12$ months, responses (range; $r^{2}=.33$ to .70 ), and initiations (range; $r^{2}=.26$ to .83 ). Analyses of social behaviors at 24 and 40 months revealed the same group of indicators for responses and initiations plus an additional response indicator (i.e., compliance). Results again supported the presence of two constructs (i.e., responses, initiations) at these ages that accounted for significant variability in these indicators; 24 months, responses (range; $r^{2}=.23$ to .80 ), and initiations (range; $r^{2}=.24$ to .74 ); 40 months, responses (range; $r^{2}=.35$ to .79 ), and initiations (range; $r^{2}=.45$ to .77 ). Finally, two models were compared with full structural equation model analyses; one with paths from response to initiating across the four age points as well as those from response to response and initiating to initiating across time. A second model included only paths within constructs across time. A comparison of these two models indicated no significant cross-construct-cross-time coefficients, $\chi^{2}(12, N=300)=7.81, p>.05$, and that the model with only within-construct paths over time demonstrated adequate fit, $\chi^{2}(343, N=)=686.60, p<.05$ (chi-square to degrees of freedom ratio not greater than 2 to 1 ; RMSEA $=.05, p>.05$, $\mathrm{GFI}=.87$, CFI $=.93$ ). Therefore, we modeled relations between parenting and social competence in two separate HLM models: responding and initiating.

Although both social age scores showed growth for all groups across 6 through $\mathbf{4 0}$ months, minimal growth is seen across all groups from 6 to 12 months. This may be due in part to regression to the mean as a result of our age score transformations. The emphasis placed in our coding scheme on certain social behaviors may also explain this minimal growth. By 6 months of age, most infants were fairly proficient in showing eye gaze behavior, positive affect, and visual orientation to the focus of mothers' requests. By 12 months, these same behaviors were the social skills most frequently observed across most infants. Although early vocalizations and gesturing were emerging, these were less frequently observed and thus not adding significantly to the change in social scores across the first year of life.

\section{Prediction of Growth in Social Skills}

The need for a curvature parameter in modeling growth in social response and initiating was determined with HLM in a similar manner as described for the cognitive-language model. Results indicated a significant curvature parameter for both models; response, $\chi^{2}(328, N=300)=488.8, p<.0001$, and initiating, $\chi^{2}(326, N=300)=506.57, p<.0001$. The variability for each of the three parameters in both models significantly differed from zero (all $p s<.0001$ ), and, therefore, intercept, slope, and curvature for the two models were entered as random effects. For each model, reliabilities for each of these three parameters, intercorrelations among parameters, and significant and nonsignificant terms predicting growth in social initiating and response ages are presented in Tables 7 and 8 . The reliabilities for the intercept and slope parameters are higher than are the reliabilities for the curvature parameters. However, the results from subsequent analyses indicate that the reliability for curvature was high enough to yield significant predictors and thus suggest there is significant nonrandom variance (Asendorpf, 1994). Nonsignificant interactions with risk and maternal warm responsiveness and maintaining for all three parameters in the response model were dropped, and nonsignificant interac- 
Table 7

Predictors of Growth in Social Initiating Skills

From 6 Through 40 Months

\begin{tabular}{|c|c|c|c|}
\hline Parameter and growth predictor & $\begin{array}{l}\text { Parameter } \\
\text { estimate }\end{array}$ & $t$ ratio & $p$ \\
\hline \multicolumn{4}{|l|}{ Child status at 18 mos: intercept ${ }^{\mathrm{a}}$} \\
\hline Constant & 2.73 & 0.57 & .57 \\
\hline SES & -0.01 & -0.29 & .77 \\
\hline Contrast $1:$ HR vs. LR/FT & 1.72 & 1.30 & .30 \\
\hline Contrast 2: LR vs. FT ${ }^{\mathrm{c}}$ & -5.31 & -1.99 & .05 \\
\hline Mental age & 2.00 & 6.38 & .000 \\
\hline Warm responsiveness & -0.04 & -0.14 & .89 \\
\hline Total stimulation & 0.02 & .87 & .38 \\
\hline Maintaining & 0.07 & 1.52 & .13 \\
\hline Directiveness & -0.01 & -0.21 & .84 \\
\hline Restrictiveness & -0.01 & -0.39 & .69 \\
\hline Maintaining: HR vs. LR/FT & 0.01 & 0.47 & .64 \\
\hline Maintaining: LR vs. FT & 0.03 & 0.56 & .57 \\
\hline Directiveness: HR vs. LR/FT & -0.06 & -2.17 & .03 \\
\hline Directiveness: LR vs. FT & 0.09 & 2.01 & .04 \\
\hline Restrictiveness: HR vs. LR/FT & 0.04 & 1.86 & .031 \\
\hline Restrictiveness: LR vs. FT & 0.00 & 0.03 & .97 \\
\hline \multicolumn{4}{|l|}{ Linear growth rate: slope ${ }^{d}$} \\
\hline Constant & -6.54 & -2.17 & .03 \\
\hline SES & 0.06 & 2.19 & .03 \\
\hline Contrast $1:$ HR vs, LR/FT ${ }^{b}$ & 0.89 & 0.88 & .37 \\
\hline Contrast 2: LR vs. $\mathrm{FT}^{\mathrm{c}}$ & -2.56 & -1.58 & .11 \\
\hline Mental age & 1.07 & 5.09 & .000 \\
\hline Warm responsiveness & 0.16 & 0.87 & .39 \\
\hline Total stimulation & 0.04 & 3.46 & .001 \\
\hline Maintaining & 0.01 & 0.43 & .66 \\
\hline Directiveness & 0.02 & 0.99 & .32 \\
\hline Restrictiveness & -0.07 & -3.12 & .002 \\
\hline Maintaining: HR vs. LR/FT & -0.03 & -1.71 & $.04 *$ \\
\hline Maintaining: LR vs. FT & 0.03 & 1.18 & .24 \\
\hline Directiveness: HR vs. LR/FT & -0.01 & -0.78 & .44 \\
\hline Directiveness: LR vs. FT & 0.02 & 1.08 & .28 \\
\hline Restrictiveness: HR vs. LR/FT & 0.03 & 2.26 & .02 \\
\hline Restrictiveness: LR vs. FT & -0.01 & -0.37 & .71 \\
\hline \multicolumn{4}{|l|}{ Nonlinear growth rate-curvature } \\
\hline Constant & 0.36 & 0.13 & .89 \\
\hline SES & 0.04 & 1.63 & .10 \\
\hline Contrast 1: $\mathrm{Hr}$ vs. LR/FT & -0.92 & -0.94 & .35 \\
\hline Contrast 2: LR vs. $\mathrm{FT}^{\mathrm{c}}$ & 1.21 & 0.78 & .43 \\
\hline Mental age & -0.22 & -1.18 & .24 \\
\hline Warm responsiveness & 0.02 & 0.09 & .93 \\
\hline Total stimulation & 0.01 & 0.96 & .34 \\
\hline Maintaining & -0.02 & -0.61 & .54 \\
\hline Directiveness & 0.02 & 0.86 & .39 \\
\hline Restrictiveness & -0.05 & -2.46 & .01 \\
\hline Maintaining: HR vs. LR/FT & -0.02 & -1.37 & .17 \\
\hline Maintaining: LR vs. FT & 0.01 & 0.19 & .84 \\
\hline Directiveness: HR vs. LR/FT & 0.03 & 1.85 & .03 \\
\hline Directiveness: LR vs. FT & -0.02 & -1.02 & .31 \\
\hline Restrictiveness: HR vs. LR/FT & 0.00 & 0.23 & .82 \\
\hline Restrictiveness: LR vs. FT & -0.01 & 0.36 & .72 \\
\hline \multicolumn{4}{|l|}{ Intercorrelations } \\
\hline Intercept & - & & \\
\hline Slope & 0.60 & - & \\
\hline Curvature & -0.29 & 0.59 & - \\
\hline
\end{tabular}

Note. Asterisk indicates one-tailed test. SES $=$ socioeconomic status; $\mathrm{HR}=$ high risk; $\mathrm{LR}=$ low risk; $\mathrm{FT}=$ full-term.

${ }^{\mathrm{a}}$ Reliability $=.64 .{ }^{\mathrm{b}}$ Contrast $1:$ HR $(-2)$ compared with LR (1) and FT (1) combined. $\quad{ }^{\mathrm{c}}$ Contrast 2: LR (-1) compared to FT (1), ${ }^{\mathrm{d}}$ Reliability $=.74 .{ }^{\mathrm{e}}$ Reliability $=, 48$. tions for all parameters with risk and warm responsiveness were dropped from the initiating model.

\section{Prediction of Growth in Social Initiating}

When examining relations with social initiating at the 18month intercept, mothers' use of early interactions that involved greater proportions of directiveness related to higher initiating ages for the HR as compared with the LR and FT children but to lower initiating ages for the LR as compared to the FT children. For restrictiveness, a significant $H R$ versus $L R$ and FT group interaction was found that indicated that mothers' use of higher proportions of restrictiveness related to lower initiating ages, but this relation was stronger for the HR children as compared with the other two groups. For all groups, higher early mental ages also predicted higher social initiating ages at 18 months of age, and a LR VLBW status predicted higher initiating ages at this intercept point when compared to a FT status (see Table 7).

Evaluation of maternal predictors of growth in social initiating (i.e., slope) revealed a significant main effect for restrictiveness but also a significant HR versus LR and FT group interaction. As depicted in Figure 2, these results indicated that mothers' use of higher proportions of restrictiveness related to slower rates of increase in all children's initiating, but this relation was stronger for the HR children compared with the other two groups. Mothers' use of higher proportions of maintaining predicted greater increases in initiating for the HR as compared with the LR and FT children. For all children, higher SES, early mental ages, and frequencies of maternal stimulation predicted a greater rate of increase in initiating ages (see Table 7).

When examining maternal predictors of nonlinear growth in initiating (i.e., curvature), the positive constant estimate, although nonsignificant, suggests some acceleration in growth in initiating at later ages. When the relation of specific maternal behaviors to this acceleration was examined, early interactions that had higher proportions of restrictiveness predicted a decreased rate of acceleration for all children. Higher proportions of maternal directiveness also predicted a decreased rate of acceleration in initiating, but this was only apparent for the HR children as compared with the other two groups (see Table 7).

\section{Prediction of Growth in Social Responses}

When examining maternal predictors of children's social response at the 18-month intercept, mothers across all groups whose early interactions involved higher proportions of directiveness had children with higher response ages. For mothers of HR children as compared with mothers of LR and FT children, early interactions that had a higher proportion of restrictiveness related to children's having lower response ages. In addition, children with higher early mental ages had higher response ages (see Table 8).

Evaluation of maternal predictors of linear growth (i.e., slope) in children's responses revealed a significant HR versus LR and FT group interaction for restrictiveness. Mothers use of higher proportions of restrictiveness related to a lower rate of increase in response ages. However, these relations were stronger 
Table 8

Predictors of Growth in Social Responsiveness Skills From 6 Through 40 Months

\begin{tabular}{|c|c|c|c|}
\hline Parameter and growth predictor & $\begin{array}{l}\text { Parameter } \\
\text { esimate }\end{array}$ & $t$ ratio & $p$ \\
\hline \multicolumn{4}{|l|}{ Child status at 18 mos: intercept } \\
\hline Constant & -8.17 & -1.80 & .07 \\
\hline SES & 0.04 & 0.93 & .35 \\
\hline Contrast $1:$ HR vs. LR/FT ${ }^{\text {b }}$ & 1.37 & 0.98 & .33 \\
\hline Contrast 2: LR vs. FT & -2.39 & -1.16 & .83 \\
\hline Mental age & 1.98 & 6.67 & .000 \\
\hline Warm responsiveness & 0.29 & 0.98 & .33 \\
\hline Total stimulation & 0.01 & 0.86 & .39 \\
\hline Maintaining & 0.03 & 0.65 & .51 \\
\hline Directiveness & 0.09 & 2.42 & .01 \\
\hline Restrictiveness & -0.03 & -0.91 & .36 \\
\hline Directiveness: HR vs. LR/FT & -0.05 & -1.82 & .06 \\
\hline Directiveness: LR vs. FT & 0.05 & 1.21 & .23 \\
\hline Restrictiveness: HR vs. LR/FT & 0.06 & 2.54 & .01 \\
\hline Restrictiveness: LR vs. FT & 0.00 & 0.13 & .89 \\
\hline \multicolumn{4}{|l|}{ Linear growth rate: slope ${ }^{d}$} \\
\hline Constant & -2.54 & -0.86 & .39 \\
\hline SES & 0.03 & 1.07 & .28 \\
\hline Contrast $1:$ HR vs. LR/FT ${ }^{b}$ & -0.36 & -0.42 & .67 \\
\hline Contrast 2: LR vs. FT & -1.18 & -0.94 & .35 \\
\hline Mental age & 0.69 & 3.43 & .001 \\
\hline Warm responsiveness & 0.15 & 0.85 & .39 \\
\hline Total stimulation & 0.03 & 3.61 & .001 \\
\hline Maintaining & 0.01 & 0.34 & .73 \\
\hline Directiveness & 0.01 & 0.48 & .63 \\
\hline Restrictiveness & -0.03 & -1.43 & .15 \\
\hline Directiveness: HR vs. LR/FT & -0.01 & -0.48 & .63 \\
\hline Directiveness: LR vs. FT & 0.03 & 1.16 & .24 \\
\hline Restrictiveness: HR vs. LR/FT & 0.03 & 2.52 & .01 \\
\hline Restrictiveness: LR vs. FT & -0.02 & -0.75 & .45 \\
\hline \multicolumn{4}{|l|}{ Nonlinear growth rate: curvature } \\
\hline Constant & 4.81 & 2.17 & .03 \\
\hline SES & 0.01 & 0.46 & .64 \\
\hline Contrast 1: HR vs. LR/FT $^{b}$ & -1.10 & -1.64 & .10 \\
\hline Contrast 2: LR vs. FT ${ }^{c}$ & 0.49 & 0.50 & .61 \\
\hline Mental age & -0.41 & -2.78 & .006 \\
\hline Warm responsiveness & -0.00 & -0.02 & .98 \\
\hline Total stimulation & 0.02 & 2.00 & .04 \\
\hline Maintaining & 0.01 & 0.36 & .72 \\
\hline Directiveness & -0.03 & -1.42 & .16 \\
\hline Restrictiveness & -0.02 & -0.98 & .32 \\
\hline Directiveness: HR vs. LR/FT & 0.02 & 1.71 & $.04 *$ \\
\hline Directiveness: LR vs. FT & -0.01 & -0.48 & .63 \\
\hline Restrictiveness: HR vs. LR/FT & -0.01 & -0.57 & .56 \\
\hline Restrictiveness: $\mathbf{L R}$ vs. FT & -0.01 & -0.70 & .48 \\
\hline \multicolumn{4}{|l|}{ Intercorrelations } \\
\hline Intercept & - & & \\
\hline Slope & -0.85 & - & \\
\hline Curvature & -0.36 & 0.18 & - \\
\hline
\end{tabular}

Note. Asterisk indicates one-tailed test. SES = socioeconomic status; $\mathrm{HR}=$ high risk; $\mathrm{LR}=$ low risk; $\mathrm{FT}=$ full-term.

${ }^{a}$ Reliability $=.61 .{ }^{b}$ Contrast $1:$ HR $(-2)$ compared with LR (1) and FT (1) combined. ' Contrast 2: LR (-1) compared to FT (1). ${ }^{d}$ Reliability $=.62 .{ }^{\circ}$ Reliability $=.28$.

for the HR children compared with the other two groups. In addition, higher early mental ages and higher frequencies of maternal stimulation averaged across the first year of life related to a greater rate of increase in response age (see Table 8).

Examination of nonlinear growth (i.e., curvature) revealed a significant constant term indicating that faster rates of growth in social response skills occur at later ages for all children. When examining the relation of maternal behaviors to this later acceleration, children whose mothers used higher proportions of early directiveness were more likely to have children who showed a decreased rate of acceleration, but this was only apparent for the HR children compared with LR and FT children. In contrast, greater frequencies of early maternal stimulation predicted that this rate of acceleration would be increased for all children. Although children with higher early mental ages were shown to have greater linear increases (i.e., slope), higher early mental ages related to a decreased rate of acceleration in later growth (see Table 8).

\section{Discussion}

We examined whether early parenting behaviors that are characterized in the literature as more optimal for children's outcomes also explain individual differences in the rate at which FT and VLBW children develop cognitive-language and social skills. Providing specialized support at a time when children's attentional and organizational skills are less mature was expected to provide a more optimal foundation for later learning. Relations between early parenting and faster growth in development were expected to be stronger for the HR VLBW children than for the LR and FT children because the maternal behaviors assessed were expected to specifically support the types of early developmental problems HR children are known to have.

A striking and consistent finding across the three models was the negative influence of higher proportions of restrictiveness on rates of growth for all children's cognitive-language and social skills. In addition to predicting less of an increase and slower rates of change for all children, the negative influence of restrictiveness was stronger for the HR VLBW children's development of cognitive-language and social skills compared with the other two groups. The literature shows consistent support for the highly negative influence of a restrictive style of parenting on children's social and cognitive outcomes ( see Rocissano et al., 1985). What has been less well examined is whether a restrictive style is particularly detrimental for children who are at risk for developmental delays due to greater biological risk. Because this maternal style does not encourage reciprocal interactions, mothers may give children the message that they are not capable of controlling their own behavior and of taking initiative.

We previously demonstrated that HR VLBW infants do not learn contingencies in the first year of life as well as LR and FT infants (Landry et al., 1985). Mothers who frequently restrict their HR infants' attempts to explore and to interact socially may make it difficult for them to learn the importance of acting on their interests because taking an active role does not result in a predictable positive response from their mothers. It is striking that children across all three groups showed faster deceleration in their cognitive-language and social initiating skills if their mothers had high levels of early restrictiveness. As independent functioning becomes more important in these skill areas toward the end of the developmental period assessed in this study, these results suggest that children whose early 


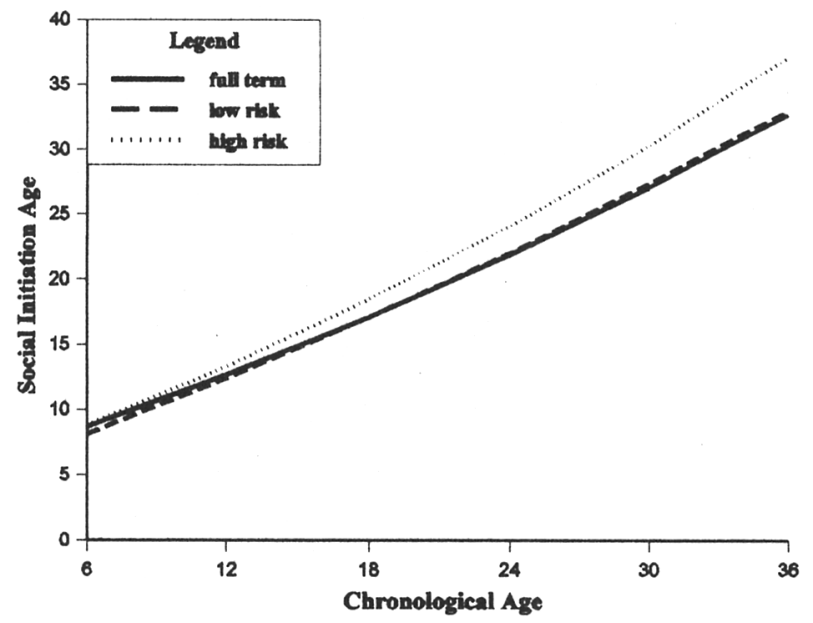

LOW RESTRICTIVENESS

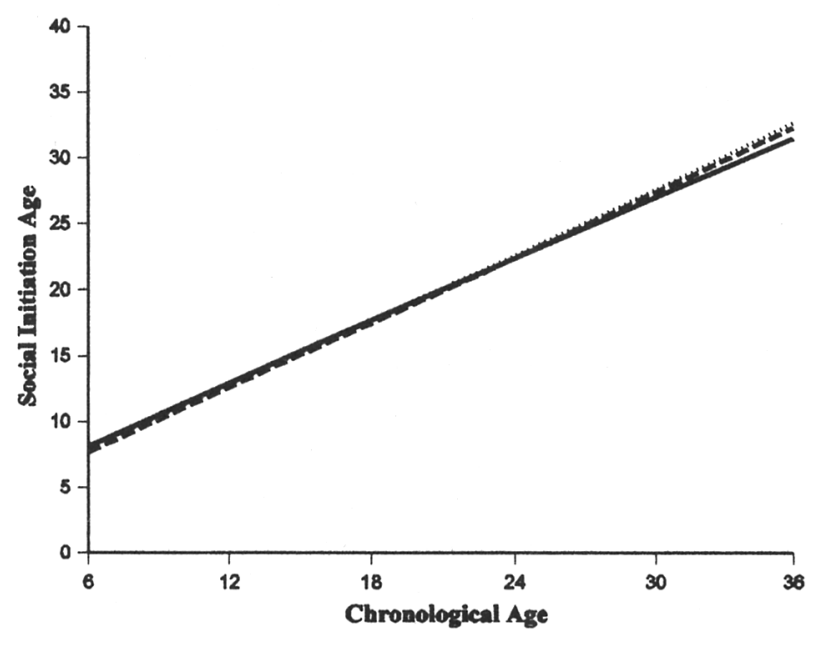

MODERATE RESTRICTIVENESS

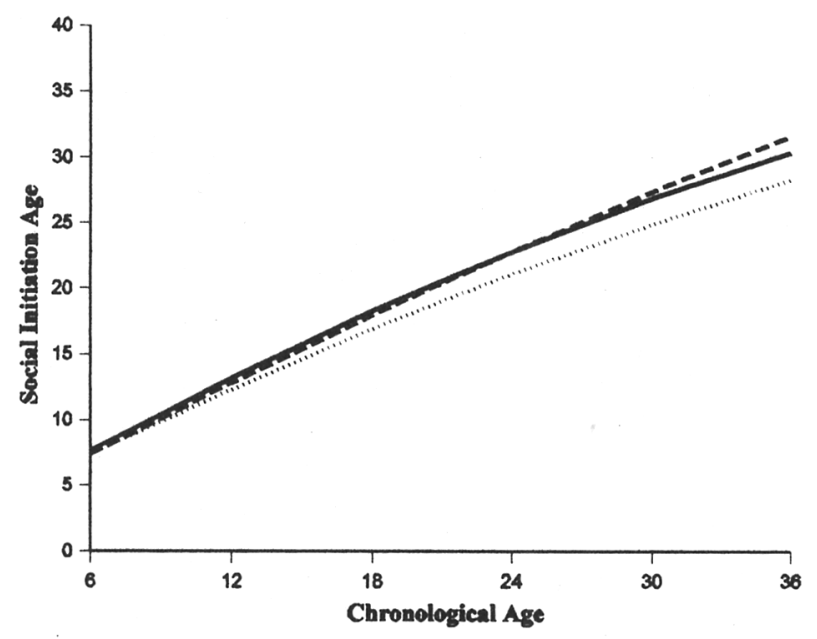

HIGH RESTRICTIVENESS

Figure 2. The relation of high, moderate, and low levels of restrictiveness with average growth in children's social initiating ages from 6 through $\mathbf{4 0}$ months of age by risk group. experiences are frequently interrupted with requests to stop doing something are not able to assume independence in their learning at a normal rate. Studies have rarely described the influence of restrictiveness on children's development as it occurs during the first year of life, but rather during the toddler and preschool period. Our findings, with a lower SES sample, suggest that it is important to focus on the impact of this style of interaction during the first year of life, particularly because mothers across all groups display a high proportion of this behavior and its long-term influence may be quite detrimental. It is important to recognize that the findings with restrictiveness may represent bidirectional influences. Children who have greater difficulty with early social skills may elicit more limit setting on their behaviors from their mothers during the first year of life, contributing to a negative interactional pattern in the dyad that may persist throughout the preschool years (Patterson, 1982).

Mothers' attempts to maintain their infants' interests predicted greater increases in cognitive-language skills for all groups and greater increases in the rate of development of social initiating for the HR VLBW children. A number of researchers theorize that maintaining children's interests positively influences cognitive skills by enhancing young children's more limited capacity to process new information because a shift in attentional focus is not required. The potential influence of mothers' maintaining is illustrated in two separate studies that show increased exploratory play for FT and VLBW infants when their mothers' requests maintained rather than redirected their attention (Landry et al., 1996) and higher language scores at 2 years of age when mothers maintained children's topics of conversation (Rocissano \& Yatchmink, 1983). Results of the current study are the first to show an influence of maintaining on rates of growth for groups of children known to vary in their rates of development. It is important to note that early maintaining may initially be elicited from mothers because of the infants' level of competence. Infants who are more cognitively competent may provide their mothers with clearer signals by which they can maintain those interests.

Maintaining may predict growth in initiating for the HR children in the present study by decreasing demands on their cognitive and attentional capacities and, in turn, facilitate their ability to organize their behavior to signal their interests. Early maintaining may not predict the same degree of growth in initiating for the FT and LR VLBW children because these two groups of children do not have the same degree of difficulty as the HR children in independently organizing their behavior. Contrary to our hypotheses, early maintaining did not relate to growth in social responding for any of the groups. One possible explanation is that responding in day-to-day exchanges (e.g., "Are you hungry?", "Give mommy a kiss.") may not place the same type of information processing demands on children as those that occur during toy-centered learning interactions or during interactions that require independent organization of social behaviors (i.e., initiating). Therefore, infants, regardless of their level of medical risk, may not require this form of early support for their attentional skills to respond.

These results also demonstrate that the way a particular maternal behavior may influence children's development can vary depending on whether one is examining relations at a single, 
early time point (i.e., intercept) versus rates of change over time. Results from the three models show that an early maternal style that is low in directiveness may provide the foundation for independent learning to be more effectively activated across this age range but may not support early skills. Mothers who used a greater proportion of directive strategies across the first year of life were more likely to have children across all groups with higher 18-month social response skills (i.e., intercept) and HR children with higher 18 -month initiating skills. There was also a trend for a positive relation between mothers' directiveness and all children's cognitive-language skills at 18 months. However, when findings with rates of development were examined, higher levels of mothers' early directiveness related to a slower rate of increase in cognitive-language development through 3 years of age for all children and to more deceleration in both social skills for the HR children as compared with the FT and LR children. A directive style may predict better 18-month performance because cognitive demands at this age require understanding actions with objects and early word usages, and performance on these skills can be enhanced by being taught with a directive approach (see Marfo, 1990). A directive style may negatively predict the curvature parameters because at later ages, cognitive demands become more complex, requiring children to integrate information. Encouraging children from early ages to make choices and to direct their learning may promote increases in their ability to integrate information across this developmental period because it provides a foundation for children to learn to solve problems independently.

At 18 months, maternal directiveness predicted all children's ability to appropriately respond during a social exchange and, for the HR children, it also appears to support taking initiative. HR children's ability to initiate may depend on mothers providing them with more direction to assist in organizing their behavior to signal their interests. However, a more directive early approach relates to slower rates of increase in both social skills for HR children across 3 years of age. Mothers of HR children may need to strike a balance in their use of early directiveness to support their children's early social skills, without compromising the promotion of later growth in independent social functioning.

We did not find strong support for a relation between early warm responsiveness with growth in children's skill development. This is confusing because strong support is found in the literature for a positive relation of mothers' early contingent responsiveness with children's later cognitive outcomes (e.g., Bornstein \& Tamis-LeMonda, 1989). Our study differs in that we evaluated the relation of this maternal behavior on rates of growth across FT and VLBW children rather than an outcome at a single age point for normally developing children. Another difference in our study from that of Bornstein is in how this maternal behavior was measured. In observations by Bornstein and Tamis-LeMonda, maternal contingent responsiveness scores were based on frequency counts and whether maternal behaviors were sequentially linked to the associated infant behavior while we used ratings to capture this style of maternal interaction. Although our criteria for these ratings included the extent to which maternal behaviors were appropriately linked to the infants' behaviors, ratings captured a general quality to the mother-infant interaction rather than a detailed account of each interchange. More detailed analyses of behaviors used in specific interchanges may be more sensitive. In the current study, we found significant findings with maintaining, directiveness, and restrictiveness, which were measured by accounting for what occurred in each maternal request. Greater measurement sensitivity for warm responsiveness may, therefore, be found with approaches that account for behaviors used in each interaction.

Our findings highlight the combined influence of early child and maternal factors in understanding ongoing development. Children's early mental and social skills contributed significantly to our understanding of growth for all three skill areas. Children who are more capable of solving problems and of using appropriate social behaviors during infancy may be more likely to show faster rates of gains, in part, because they make it easier for their mothers to respond in more positive ways. In previous studies, we have demonstrated slower rates of growth in cognitive and social skills for VLBW as compared to FT children (Landry et al., 1997). In the present study, medical risk alone did not predict the growth parameters but rather was important in demonstrating that specific maternal behaviors explain individual differences in biologically at-risk children's rate of development. Also, the general amount of stimulation provided by the mothers in the first year of life predicted rates of growth in cognitive-language and social skills. In other studies, higher Home Observation for Measurement of the Environment (Caldwell, 1972) scores, reflecting general amounts of early stimulation, predicted higher cognitive skills at 3 and 4 years of age for normally developing (Bradley \& Caldwell, 1976) and preterm (Bee et al., 1982) children. Together, these findings demonstrate that the amount of stimulation provided for children during the infancy period is an important factor in understanding children's development. Differences in families' SES also predicted growth in cognitive-language and social initiating skills, suggesting that there are aspects of the early caretaking environment not accounted for in the specific maternal behaviors included in our models that are important in understanding growth in children's skills.

These results emphasize the importance of early parenting that is sensitive to children's focus of interest and is not highly controlling or restrictive of children's behaviors for enhancing gains in children's cognitive-language and social development. These results should be interpreted in light of the inclusion of mostly lower income families. However, because many of our results are consistent with studies that only include middle-class mother-infant dyads, they may assist in the generalizability of these parenting behaviors for promoting more optimal child development. Although this study focused on the effects of early parenting on rates of change, questions remain as to whether relations found with these early parenting behaviors represent a more stable parenting style over time. If so, then effects could be due to consistency in maternal behaviors rather than to an effect of early parenting on rates of development. The present results highlight the importance of understanding those parenting behaviors that support the special needs of young infants and that help them establish a solid foundation for later gains. Future research is still needed to examine what mothers do at later points in children's development to foster growth in later milestones. 


\section{References}

Akhtar, N., Dunham, F., \& Dunham, P. (1991). Directive interactions and early vocabulary development: The role of joint attentional focus. Journal of Child Language, 18, 41-49.

Asendorpf, J. B. (1994). The malleability of behavioral inhibition: A study of individual developmental functions. Developmental Psychology, 30, 912-919.

Bakeman, R., \& Brown, J. V. (1980). Early interaction: Consequences for social and mental development at 3 years. Child Development, 51 , 437-447.

Baumrind, D. (1966). Effects of authoritarian parental control on child behavior. Child Development, 37, 887-907.

Bayley, N. (1969). Bayley Scales of Infant Development. New York: Psychological Corporation.

Bee, H. L., Barnard, K. E., Eyres, S. J., Gray, C. A., Hammond, M. A., Spietz, A. L., Snyder, C., \& Clark, B. (1982). Prediction of IQ and language skill from perinatal status, child performance, family characteristics, and mother-infant interactions. Child Development, 53, 1134-1156.

Belsky, J., Goode, M. K., \& Most, R. K. (1980). Maternal stimulation and infant exploratory competence: Cross sectional, correctional, and experimental analyses. Child Development, 51, 1163-1178.

Bendersky, M., \& Lewis, M. (1990). Early language ability as a function of ventricular dilatation associated with intraventricular hemorrhage. Developmental and Behavioral Pediatrics, 11, 17-21.

Bloom, L., Rocissano, L., \& Hood, L. (1976). Adult-child discourse: Developmental interaction between information processing and linguistic knowledge. Cognitive Psychology, 8, 521-552.

Bornstein, M., \& Tamis-LeMonda, C. S. (1989). Maternal responsiveness and cognitive development in children. In M. H. Bornstein (Ed.), Maternal responsiveness: Characteristics and consequences (pp. 49-61). San Francisco: Jossey-Bass.

Bradley, R. H., \& Caldwell, B. M. (1976). The relation of infants' home environment to mental test performance at fifty-four months: A followup study. Child Development, 47, 1172-1174.

Bruner, J. (1977). Early social interaction and language acquisition. In H. R. Schaffer (Ed.), Studies in mother-infant interaction (pp. 271 289). New York: Academic Press.

Bryk, A. S., \& Raudenbush, S. W. (1992). Hierarchical linear models: Applications and data analysis methods change. Newbury Park, CA: Sage.

Butterworth, G. (1995). Origins of mind in perception and action. In C. Moore \& P. J. Dunham (Eds.), Joint attention: Its origins and role in development (pp. 29-40). Hillsdale, NJ: Erlbaum.

Caldwell, B. (1972). HOME Inventory. Little Rock: University of Arkansas.

Cook, N. R., \& Ware, J. H. (1983). Design and analysis methods for longitudinal research. Annual Review of Public Health, 4, 1-23.

Crockenberg, S., \& Litman, C. (1990). Autonomy as competence in 2year-olds: Maternal correlates of child defiance, compliance, and selfassertion. Developmental Psychology, 26, 961-971.

Crocker, L., \& Algina, J. (1986). Introduction to classical and modern test theory. New York: Harcourt Brace Jovanovich.

Cronbach, L. J., Gleser, G. C., \& Rajaratnam, N. (1963). Theory of generalizability: A liberalization of reliability theory. British Journal of Mathematical and Statistical Psychology, 16, 137-173.

Emde, R. N. (1985). The affective self: Continuities and transformation from infancy. In J. Call \& E. Galenson (Ed.), Frontiers of infant psychology (Vol. 2, pp. 38-54). Baltimore: University Park.

Goldberg, S., Lojkasek, M., Gartner, G., \& Corter, C. (1989). Maternal responsiveness and social development in preterm infants. In $\mathbf{M}$. $\mathbf{H}$. Bornstein (Ed.), Maternal responsiveness: Characteristics and consequences, (pp. 89-103). San Francisco: Jossey-Bass.

Hedrick, D. L., Prather, E. M., \& Tobin, A. R. (1975). Sequenced inven- tory of communication development. Seattle: University of Washington Press.

Hollingshead, A. B. (1975). Four factor index of social status. (Available from the Department of Sociology, Yale University, P.O. Box 1965, New Haven, CT.

Kopp, C. B. (1982). Antecedents of self-regulation: A developmental perspective. Developmental Psychology, 18, 199-214.

Kuczynski, L. (1984). Socialization goals and mother-child interactions: Strategies for long-term and short-term compliance. Developmental Psychology, 20, 1061-1073.

Kuczynski, L., \& Kochanska, G. (1990). Development of children's noncompliance strategies: From toddlerhood to age 5. Developmental Psychology, 26, 398-408.

Landry, S. H. (1995). The development of joint attention in premature low birth weight infants: Effects of early medical complications and maternal attention-directing behaviors. In C. Moore \& P. Dunham (Eds.), Joint attention: Its origins and role in development (pp. 223250). Hillsdale, NJ: Erlbaum.

Landry, S. H., \& Chapieski, M. L. (1989). Joint attention and infant toy exploration: Effects of Down syndrome and prematurity. Child Development, 60, 103-118.

Landry, S. H., Chapieski, L., Richardson, M., Palmer, J., \& Hall, S. (1990). The social competence of children born prematurely: Effects of medical complications and parent behaviors. Child Development, 61, 1605-1616.

Landry, S. H., Denson, S. E., \& Swank, P. R. (1997). Effects of medical risk and socioeconomic status on the rate of change in cognitive and social development for low birth weight children. Journal of Clinical and Experimental Neuropsychology, 19, 261-274.

Landry, S. H., Fletcher, J. M., Denson, S., \& Chapieski, L. (1993). Longitudinal outcome for low birth weight infants: Effects of intraventricular hemorrhage and bronchopulmonary dysplasia. Journal of Clinical and Experimental Neuropsychology, 15, 205-218.

Landry, S. H., Garner, P. W., Pirie, D., \& Swank, P. R. (1994). Effects of social context and mothers' requesting strategies on Down's syndrome children's social responsiveness. Developmental Psychology, 30, 293302.

Landry, S. H., Garner, P., Swank, P., \& Baldwin, C. (1996). Effects of maternal scaffolding during joint toy play with preterm and full-term infants. Merrill-Palmer Quarterly, 42, 177-199.

Landry, S., Leslie, M., Fletcher, J., \& Francis, D. (1985). Visual attention skills of premature infants with and without intraventricular hemorrhage. Infant Behavior and Development, 8, 309-322.

Landry, S. E., Miller-Loncar, C. L., \& Smith, K. E. (in press). The development of social communicative competence in full-term and preterm infants: Effects of mother's support. In U. Kirk \& V. L. Molfese (Eds.), Developmental variations in language and learning. Hillsdale, NJ: Erlbaum.

Leung, E. H. L., \& Rheingold, H. (1981). Development of pointing as a social gesture. Developmental Psychology, 17, 215-220.

Lewis, M., \& Goldberg, S. (1969). Perceptual-cognitive development in infancy: A generalized expectancy model as a function of motherinfant interaction. Merrill-Palmer Quarterly, 15, 81-100.

Londerville, S., \& Main, M. (1981). Security of attachment, compliance, and maternal training methods in the second year of life. Developmental Psychology, 17, 289-299.

Maccoby, E., \& Martin, J. A. (1983). Socialization in the context of the family: Parent-child interaction. In P. H. Mussen (Series Ed.) \& E. M. Hetherington (Vol. Ed.), Handbook of child psychology: Vol. 4. Socialization, personality, and social development (4th ed., pp. 1102). New York: Wiley.

MacDonald, K. (1992). Warmth as a developmental construct: An evolutionary analysis. Child Development, 63, 753-773.

Marfo, K. (1990). Maternal directiveness in interactions with mentally 
handicapped children: An analytical commentary. Journal of Child Psychology and Psychiatry, 31, 531-549.

Matas, L., Arend, R., \& Sroufe, A. (1975). Continuity of adaptation in the second year: The relationship between quality of attachment and later competence. Child Development, 49, 547-556.

Maxwell, S. E., \& Delaney, H. D. (1990). Designing experiments and analyzing data: A model comparison perspective. Belmont, CA: Wadsworth.

McCall, R. B. (1977). Challenges to a science of developmental psychology. Child Development, 48, 333-344.

Olson, S. L., Bates, J. E., \& Bayles, K. (1984). Mother-infant interaction and the development of individual differences in children's cognitive competence. Developmental Psychology, 20, 166-179.

Patterson, G. R. (1982). Coercive family processes. Eugene, OR: Castalia.

Parpal, M., \& Maccoby, E. E. (1985). Maternal responsiveness and subsequent child compliance. Child Development, 56, 1326-1334.

Pedhazur, E. J. (1982). Multiple regression in behavioral research: Explanation and prediction (2nd Ed.). Fort Worth, TX: Holt, Rinehart \& Winston.

Plunkett, J. W., \& Meisels, S. J. (1989). Socioemotional adaptation of preterm infants at three years. Infant Mental Health Journal, 10, 117131.

Power, T. G., \& Chapieski, M. L. (1986). Childrearing and impulse control in toddlers: A naturalistic investigation. Developmental Psychology, 22, 271-275.

Rocissano, L., Slade, A., \& Lynch, V. (1985). Dyadic synchrony and toddler compliance. Developmental Psychology, 56, 1326-1334.

Rocissano, L., \& Yatchmink, Y. (1983). Language skill and interaction patterns in prematurely born toddlers. Child Development, 54, 12291241.
Rovee-Collier, C. (1995). Time windows in cognitive development. Developmental Psychology, 31, 147-169.

Sax, G. (1980). Principles of educational and psychological measurement and evaluation. Belmont, CA: Wadsworth.

Scaife, M., \& Bruner, J. S. (1975). The capacity for joint visual attention in the infant. Nature, 253, 265-266.

Schaffer, H. R., \& Crook, C. K. (1980). Child compliance and maternal control techniques. Developmental Psychology, 16, 54-61.

Smith, K. E., Landry, S. H., Swank, P. R., Baldwin, C., Denson, S., \& Wildin, S. R. (1996). The relation of medical risk and maternal stimulation with preterm infants' development of cognitive, language, and daily living skills. Journal of Child Psychology and Psychiatry, 7, 855-864.

Thorndike, R. L., Hagen, E. P., \& Sattler, J. M. (1986). Stanford-Binet Intelligence Scale: Fourth edition. Chicago: Riverside.

Tomasello, M., \& Farrar, J. (1986). Joint attention and early language. Child Development, 57, 1454-1463.

Vohr, B., Bell, E. F., \& Williamson, O. H. (1982). Infants with bronchopulmonary dysplasia. American Journal of Diseases in Childhood, 136, 443-447.

Weiss, B., Dodge, K. A., Bates, J. E., \& Pettit, G. S. (1992). Some consequences of early harsh discipline: Child aggression and a maladaptive social information processing style. Child Development, 63, $1321-1335$.

Willett, J. B. (1989). Some results on reliability for the longitudinal measurement of change: Implications for the design of studies in individual growth. Educational and Psychological Measurement, 49, $587-602$.

Received August 12, 1996

Revision received May 19, 1997

Accepted May 27, 1997 